\title{
Margaret McCartney: The great QOF experiment
}

\author{
Margaret McCartney general practitioner
}

Glasgow

It's April, and Scotland is abandoning the quality and outcomes framework (QOF) general practitioner contract —unlike in England and Wales, where it will remain, allegedly in lighter form. Currently, all GPs are paid basic rates for each patient registered (no matter how many times the patient attends), for points on the QOF, and for additional services on top (from contraceptive implants to prescribing reviews).

The framework creates perverse incentives. Administration is mainly by computer: unless we code, we don't get paid. There are quality points for encouraging people to stop smoking. But the GP loses money even if a patient had never smoked and the GP hasn't asked whether the patient started in the past five years. If patients are eligible for the flu vaccine but don't want it, the GP loses money for missing the target. GPs in England were paid for screening people for dementia, an entirely non-evidence based activity, until the end of March. And, if GPs ignore the reason why a patient came but instead tick lots of boxes, they may lack morals but can at least pay their staff.

GPs are independent providers but are tethered by an inflexible and stupid NHS contract that possibly organised us better at the start but is now strangling us from within. Were I truly a private, non-NHS based GP interested in profitable practice, I'd do executive health checks for rich people with a bit of Botox on the side. NHS general practice doesn't do this. We're not just micromanaged but "nano-nagged" into compliance with the government's will.

Scotland is launching a "peer led, values driven" contract, apparently, which will involve nurses and pharmacists working to "the top of their licence" to offset the multiple vacancies in general practice. A trial is running near Glasgow that makes the
GP the "senior decision maker" among a large team of other professionals. I worry about taking more responsibility for people mainly working to protocols-is this safe, or better?

The best contract would be based on mutual respect, professional values, trust, and transparency. If we could have a fair contract, I'd rather be employed directly by the NHS (as is the case with consultants) rather than through a contract that distracts from good patient care.

Over a year ago our practice lost money for supposedly failing to have palliative care meetings according to the contract. We had these meetings every three months, to the letter of the contract, but we were penalised for not having them every 12 weeks. After several appeals the government eventually agreed that we had indeed done the work. Bravo. The cost of the appeal paperwork probably exceeded the refund. This is not simply wasteful: for practices disputing bigger sums, such delays could spell disaster.

There may be a glimmer of hope, however. What will happen next is a great big uncontrolled contract experiment, with England versus Scotland. For those of us saying goodbye to the quality and outcomes framework, wish us luck.

Competing interests: See www.bmj.com/about-bmj/freelancecontributors/margaret-mccartney.

Provenance and peer review: Commissioned; not externally peer reviewed.

Published by the BMJ Publishing Group Limited. For permission to use (where not already granted under a licence) please go to http://group.bmj.com/group/rights-licensing/ permissions 